The Quarterly Journal of Austrian Economics

VOLUME 23 | NO. 1 | 33-45 | Spring 2020

WWW.QJAE.ORG

\title{
ON THE IMPOSSIBILITY OF Intellectual Property
}

\author{
JAKUb BożYDAR WiśNIEWSKI* \\ JEL Classification: K00, L26, O34, P48
}

\begin{abstract}
AвstRAct: The concept of intellectual property (IP) has been variously criticized as incompatible with natural rights and detrimental to the dissemination of innovations. In this paper I argue that it can be criticized on an even more fundamental level-namely as a praxeological impossibility. More specifically, it is suggested that since ideas are not economic goods, but preconditions of action, and since physical goods transformed by ideas become as heterogeneous (and thus as intellectually unique) as the individuals who enact such transformations, no economic goods can be meaningfully designated as appropriable in virtue of embodying the objectively definable value of one's intellectual labor. In view of the above, I subsequently suggest that IP protection laws constitute an exceptionally arbitrary and thus exceptionally disruptive form of interventionism directed against the very essence of the entrepreneurial market process.
\end{abstract}

\section{INTRODUCTION}

The concept of intellectual property (IP) has been criticized 1 from a number of distinct perspectives. Proponents of libertarian ethics have criticized it as incompatible with the axiom of

\footnotetext{
*Jakub Bożydar Wiśniewski (jakub@cantab.net) is an assistant professor at the Institute of Economics at the University of Wroclaw and an affiliated scholar with the Ludwig von Mises Institute Poland.
} 
self-ownership and the resultant structure of natural rights. More specifically, they have pointed out that the category of property applies exclusively to scarce goods, while ideas - that is, the fruits of intellectual labor-are superabundant in virtue of their infinite replicability. Thus, forcibly restricting their replication amounts to a major act of aggression against the bodily integrity and physical property of the replicating agent (Kinsella 2008).

On the other hand, mainstream economists have demonstrated that patents and copyrights, far from promoting innovation, actually hinder economic development and Schumpeterian creative destruction. This is due to the fact that patent and copyright holders are effectively intellectual monopolists, capable of nipping in the bud the commercial development of any given idea (Boldrine and Levine 2008).

While acknowledging the validity and significance of the above criticisms, this paper offers a different take on the titular concept. Instead of suggesting that intellectual property is morally indefensible or economically harmful, it suggests that it is praxeologically impossible. In other words, this paper suggests that intellectual property laws constitute not so much an attempt at monopolizing a praxeologically distinct category of resources, but rather an arbitrary curtailment of entrepreneurial initiatives aimed at resource heterogenization. This, in turn, implies that the so-called protection of intellectual property creates not so much "intellectual monopolists," but rather uninvited institutional co-owners (Hülsmann 2006) of their potential business competitors' arbitrarily selected physical property.

The following section states the argument in more detail. Section 3 considers some potential counterarguments to the proposition, and section 4 concludes with a presentation of some of its further ramifications.

\section{THE ARGUMENT}

The fundamental insight of the marginalist-subjectivist tradition in economics is the observation that what makes a good is not its physical characteristics, but its ability to enter into causal relationships with subjective preference scales of purposive agents. 
Thus, even physically identical goods may differ significantly in terms of their economic value in virtue of their differing causal histories and ideational connections.

However, this crucial emphasis on the subjective nature of economic value does not change the fact that genuine economic goods, in order to qualify as such, have to exhibit objective physical scarcity. Otherwise they are not goods, but the "general conditions" of action (Rothbard 2004, 4). In other words, the marginalist-subjectivist tradition-particularly as exemplified by the Menger-Mises branch-avoids the twin pitfalls of hypersubjectivism and panphysicalism: it postulates that physically scarce objects become economic goods by being "mixed" with the ideational processes of intentional beings.

Hence, ideation turns out to be a psychological rather than a praxeological activity-in and of itself it does not fall within the purview of economic analysis, nor, by extension, within the purview of property valuation. It is only when it is translated into action that it becomes a fundamental datum of economic theory and history. And yet, as soon as it enters the realm of demonstrated preferences, it inevitably heterogenizes the resulting goods, thereby ensuring their intellectual and valuational distinctness.

This is because human action is necessarily future oriented and thus entrepreneurial in the broad sense of the term-it consists not in frictionless adjustment of supply and demand, but in the deployment of scarce means toward specific ends to be accomplished in the uncertain future (Salerno 2008). Hence, ideas, viewed as preconditions of agency, are never, strictly speaking, replicatedinstead, they are adapted to one's specific circumstances, plans, and capabilities. This, in turn, implies that as soon as a particular agent transforms particular physical objects in accordance with a given idea-even if this idea is "borrowed" from someone else-they become unique goods, infused with his unique productive touch. It should be noted here that this argument is independent of the contention that property rights apply exclusively to the physical integrity of a resource, not to its value, since the latter derives entirely from the mental states of all those individuals who are interested in putting it to some use (Hoppe and Block 2002). Although few may be willing to reject this contention in full and endorse the notion 
that maintaining the value of one's resources can extend to owning others' mental states, some may be willing to concede the inadmissibility of certain actions that diminish the value of another's assets. Underselling the originator of a "novel product" by offering exact replicas of his merchandise could be thought of as a canonical example here. However, the argument advanced in the present paper uproots this issue entirely, since it points out that physically identical products cannot be regarded as identical in terms of the sources of their value, thus making their putative ownership and their potential positive externalities a moot point.

This observation is exceptionally striking in the context of entrepreneurship narrowly conceived-that is, in the context of exercising the ownership function over capital structures of production created and recreated under conditions of uncertainty (Foss and Klein 2012). After all, the essential determinant of the success of any given business plan is not the physical capabilities of the resources owned by a given businessman, nor even the objectively definable ideas embodied in them, but the subjective evaluation of the potential residing in these and other elements of the overall entrepreneurial vision and the corresponding capital stock (Kirzner 1997). Objectively definable inventions are technical, not economic, phenomena-it is only when they help bring about subjectively conceived innovations that they contribute to economic growth and development (McCloskey 2010). This is by no means simply a repetition of the anti-IP argument that an idea is a general prerequisite of production and not subject to ownership. It is also the realization that, as far as their productive potential is concerned, ideas implemented in concrete processes of production are entirely dissimilar to ideas conceived in abstract terms. Thus, to regard all physical objects whose creation involved some use of the fruits of one's mental labor as falling within the ambit of one's "intellectual property" is to commit a fundamental categorical mistake-i.e., to confuse the results of subjective plans with their objective mental preconditions.

If, on the other hand, one were to claim that it is precisely the specific conceptual content of those mental preconditions that can be subjected to intellectual property protection, then an equally flagrant categorical mistake would be made. After all, such a claim would amount to trying to obtain exclusive use not of the results of any given action, but of a necessary prerequisite of a potentially infinite 
range of actions. In other words, it would amount to trying to put a price tag on something that is naturally priceless —on something that is not just contingently nonscarce (as so-called free goods are), but is necessarily so (as all general conditions of action have to be).

To use a specific example, this would involve attempting to obtain exclusive use not of any particular product of, say, spelling or singing, but of the very concepts of spelling or singing. Taken to its ultimate conclusion, such an approach would paralyze all human action, destroying humankind almost on the spot by making everyone unsure of whether engaging in perfectly mundane activities violates someone else's intellectual property rights. And if one tried to avoid this conclusion by suggesting that it is only sufficiently complex concepts that merit this kind of exclusive appropriation, one natural response would be to point out that such a suggestion smacks of sheer legalistic arbitrariness, since it has to rely on a purely discretionary standard of "sufficient complexity." Admittedly, making it a matter of pure legal convention which ideas are subject to IP protection would not be a logically incoherent move, but it would be a move bereft of any appeal to economic justification. More specifically, it would offer no support for the claim that the purpose of licensing the use of complex concepts is to allow their authors to reap their full market value, since it would not involve laying down any precise methods of measuring the extent to which the market value of any given good derives from its embodying any such concept (Cordato 1992, 80).

Furthermore, it has to be borne in mind that all entrepreneurial activity involves resource heterogenization (Lewin and Baetjer 2011), even if it does not consist in the Schumpeterian kind of entrepreneurship, which is typically associated with the introduction of innovations and other quintessentially conceptual tasks. Hence, for instance, buying a trademarked product and simply relocating it from a relatively saturated market to a relatively unsaturated one in order to sell it at a profit suffices to create a substantially new product, associated with uniquely specific preference scales, valuational conditions, and organizational structures. In fact, in today's age of electronic transactions an act of physical relocation is not even necessary: it suffices to engage in online arbitrage to heterogenize physically and conceptually identical goods in a productive manner. After all, if all human action is broadly entrepreneurial-that is, it 
requires creative confrontation with the uncertain future-then exploiting arbitrage opportunities is solidly innovative in its own right (Kirzner 2009).

In other words, even, say, using a general scientific formula in production without in any way altering it should count as an instance of adaptation rather than replication, since its successful commercialization requires integrating it with a specific, time- and space-bound capital structure of production. To repeat, ideational replication is a purely mental operation, and it is only entrepreneurial implementation of replicated ideas that can be economically meaningful in this context, since only the latter can be economically profitable or unprofitable, and thereby also more or less successful in addressing the problem of natural (i.e., nonartificial) scarcity.

Moreover, it must be stressed that the argument presented here is not reducible to the more familiar contention that ideas cannot be subject to property rights, since rights are, by definition, enforceable claims, with the "force" component tying in to the physical aspect of human control over scarce resources. Although this contention is perfectly reasonable, it does not immediately answer the objection that the originator of a certain idea may regard himself as a partial owner of all the scarce resources that in some degree embody its distinctive conceptual features. Of course, at this point one might make a solid case that the creative process, although certainly capable of increasing the value of specific goods, nevertheless does not automatically imply ownership of them, be it complete or partial. This, however, would shift the discussion to the normative level, having to do with defining the ethical or legal criteria of genuine appropriation. This argument is purely praxeological: it points out that there is no necessary valuational link between the conceptual features of ideas contemplated in abstract terms and the conceptual features of specific goods that incorporate those ideas.

In other words, the process of ideation might be thought of in terms of identifying potential profit opportunities, but from a realistically conceived entrepreneurial standpoint such opportunities are only imagined rather than discovered (Klein 2008). And since the fruits of one's imagination can be translated into actual business ventures in an endless variety of ways, it is incoherent to claim that the value of imagined profit opportunities can be automatically 
imputed to their actually exploited counterparts, entitling the originators of the former to the proceeds from the latter.

In sum, the subjectivist theory of value coupled with a praxeological understanding of the market process leads to the conclusion that, economically speaking, intellectual property is a contradiction in terms. In short, ideas are not economic goods, but preconditions of action, while physical goods transformed by ideas become as heterogeneous (and thus as intellectually unique) as the individuals who enact such transformations. This, in turn, implies that as important as it is to point out the efficiency-reducing and normatively troubling consequences of so-called intellectual property protection, it is possible to raise doubts about the concept on an even more fundamental, purely logical level.

\section{POTENTIAL COUNTERARGUMENTS}

Let us now analyze some potential counterarguments to the suggestion advanced in the present paper.

First, it might be claimed that, regardless of one's views on the normative aspects of the titular concept, it is an overstatement to deny its descriptive coherence. After all, one might say, it is perfectly reasonable to define the fruits of one's intellectual labor as goal-specific technical recipes, ${ }^{1}$ readily identifiable in terms of the specific material effects that their implementation produces. This, in turn, should make it conceptually unobjectionable to designate the goods that embody such effects as bearing the marks of one's intellectual property, even if we do not believe that such "property" is associated with enforceable natural rights or economically beneficial consequences.

The main problem with this suggestion is that, once again, it conceives of goods in technical rather than economic terms and treats ideas as if they were praxeological rather than psychological factors. Since, however, economics deals with subjective evaluations embodied in demonstrated preferences, not with scientific discoveries and their technical content, it must reject the notion that

\footnotetext{
${ }^{1}$ For the purpose of this paper, the terms "recipe," "idea," and "concept" are treated as interchangeable.
} 
there always exists a unique, objective description of the way in which any given good can usefully incorporate a technical recipe. On the contrary, subjectivist economics, coupled with a mature theory of capital and entrepreneurship, clearly recognizes the fact that productive factors are essentially characterized in terms of their subjectively perceived attributes, functions, and uses (Foss, Foss, Klein, and Klein 2007). Hence, there is a potentially infinite number of ways in which any given technically defined object can be imbued with the fruits of entrepreneurial creativity, alertness, and foresight, thereby becoming not just conceptually novel, but also endowed with unique economic value.

Another objection that might be leveled against the titular contention is that it cannot claim universal economic validity, since it refers to a strictly normative concept (i.e., property), while economics is a positive science. Thus, one might argue, it is a category mistake to ascribe inherent incoherence to a phenomenon whose definition is ultimately a matter of legal convention or moral imagination.

The primary error of this counterargument lies in confusing the value freedom of economics with its supposed value irrelevance. Although clearly value-free as far as the contents of its theorems are concerned, economics is crucially dependent on the evaluative and normative concepts contained in its descriptions of the catallactic order (Casey 2012). For instance, the theorem of the impossibility of rational economic calculation under socialism clearly refers to the importance of certain normative institutions (private property in the means of production, free exchange of private property titles, etc.), but it does so exclusively in order to elucidate the nature of the corresponding logically necessary causal relations, without proclaiming their ethical desirability. By the same token, the theorem in question also demonstrates that certain normative visions-such as that of an economically thriving socialist commonwealth-are not so much ethically wrong as they are inherently unviable. To put it differently, ethical evaluations of intrinsically incoherent concepts are inevitably futile, since they run afoul of the principle of "ought implies can," which often reveals such concepts to be misleading placeholders for something altogether different.

Thus, the fact that the titular contention refers to a normative concept in no way detracts from its strictly positive character. 
After all, it does not matter in this context whether or not one endorses the notion of intellectual property on ethical groundswhat matters is that such an endorsement cannot be couched in economically meaningful language. Consequently, the argument of this text does not violate the distinction between the positive and the normative-instead, it aims at demonstrating that it is the proponents of intellectual property who necessarily violate the distinction between the psychological and the praxeological.

At this point, one might argue that the above train of thought rests on the dubious premise that if an idea is by nature a general condition of action, this cannot be changed by legal enactment. In fact, however, no such premise is presupposed. Although it is clearly possible to legislate artificial scarcity into existence, it is impossible to ground such legislation in praxeologically meaningful facts. In other words, although it is possible to prosecute individuals or organizations for the supposed unlawful use of another's ideas, it does not change the purely praxeological observation that anchoring any given abstract idea in the specific circumstances of one's individual venture turns it into a fundamentally distinct idea, with no necessary valuational link between the two akin to that postulated by the Mengerian law of imputation. Hence, appealing to the conceivability of artificial scarcity in no way impugns the value freedom of this paper's contention.

Finally, it might be suggested that the supposed economic coherence of the notion of intellectual property can be established by pointing to the specificity of the interventionist effects caused by IP protection laws. If, for instance, one subscribes to the claim that such laws hinder economic development and the corresponding creation and dissemination of innovations, then one implicitly recognizes the existence of a special category of goods whose preemptive appropriation by patent and copyright holders leads to economically suboptimal results. Thus, one might argue, intellectual property emerges as an economically meaningful concept in virtue of the economically meaningful effects of its legal enforcement.

The chief weakness of the above contention is the implicit assumption that praxeologically specific consequences must be associated with a praxeologically distinct category of goods in order to retain their analytical meaningfulness. It is the case, 
however, that they might as well be associated with a praxeologically distinct kind of activities. For example, in the context under consideration it might be suggested that IP protection laws hamper not so much the production and dissemination of "intellectual goods," but the very process of heterogenization of goods-that is, the process whereby physically scarce objects become increasingly differentiated through their association with individual entrepreneurial visions. In other words, IP laws might be plausibly regarded not as a means of preemptive appropriation of "intellectual goods," but as a tool for implementing the principles of "conservative socialism" (Hoppe 1989, chap. 5). Hence, it seems perfectly feasible to recognize the economically harmful effects of interventions aimed at the suppression of entrepreneurial utilization and reutilization of generally accessible ideas without being simultaneously committed to accepting the economic meaningfulness of the concept of intellectual property.

In sum, far from being an exaggeration, the claim that so-called intellectual property is incoherent as an economic notion appears to be a solidly justifiable proposition. Let me now conclude by briefly exploring some of its further analytical ramifications and practical implications.

\section{CONCLUSION}

If intellectual property is indeed a praxeologically meaningless concept, then, as proposed in the previous section, IP laws do not prevent entrepreneurs from utilizing freely a specific, precisely definable category of goods, but instead serve as a pretext for essentially arbitrary acts of opportunistic interventionism. This indicates that they are far more capable of paralyzing the operation of the market process than is suggested by the traditional arguments centered on the economically stifling influence of "intellectual monopolies." More concretely, IP laws' definitional arbitrariness appears particularly capable of saddling entrepreneurs with a highly troublesome layer of regime uncertainty (Higgs 1997), which does not generate additional (though predictable) costs for entrepreneurial activity so much as it makes such activity essentially unpredictable on the institutional level (Kinsella 1995, 150-51). 
Furthermore, the laws in question are especially likely to cripple the operations of specifically "Schumpeterian" firms (Mueller 2003, chap. 4), that is, those that rely exceptionally heavily on creating value through resource heterogenization based on ingenious adaptation of existing technical recipes. Such firms, which are typically at the forefront of robust economic development, are especially exposed to the arbitrary interventionism of the established players, who are constantly on the lookout for excuses to accuse the newcomers of "intellectual free riding." In addition, this kind of environment gives the management of Schumpeterian firms an extra incentive to join the establishment's interventionist game as soon as possible, thereby perpetuating and further strengthening the vicious circle of rent seeking, cronyism, and enforced economic petrification.

Finally, the unhampered entrepreneurial transformation of various technical concepts is a phenomenon whose continuation is particularly important to a globally interconnected and organizationally complex society. If such a society suddenly becomes irresponsive to the economic challenges continually generated by its dynamically changing environment, which is bound to happen under conditions of repressed resource heterogenization, it will fall victim to institutional fragility (Taleb 2012) and become incapable of sustaining its complexity, ultimately collapsing under its own weight.

In conclusion, since intellectual property is a praxeologically incoherent term, IP laws turn out to constitute an exceptionally arbitrary and thus exceptionally disruptive form of interventionism directed against the very essence of the entrepreneurial market process (Kirzner 2017). Hence, intellectual property laws should be viewed as an even more fundamental obstacle to robust economic development than has been suggested by hitherto prevailing arguments.

\section{REFERENCES}

Boldrine, Michele, and David K. Levine. 2008. Against Intellectual Monopoly. New York: Cambridge University Press.

Casey, Gerard. 2012. "Ethics and Economics: Friends or Foes?." In Human Destinies: Philosophical Essays in Memory of Gerald Hanratty, ed. Fran O'Rourke. Notre Dame, Ind.: University of Notre Dame Press. 
Cordato, Roy E. 1992. Welfare Economics and Externalities in an Open Ended Universe: A Modern Austrian Perspective. Boston: Kluwer Academic Publishers Group.

Foss, Nicolai, and Peter G. Klein. 2012. Organizing Entrepreneurial Judgment: A New Approach to the Firm. Cambridge: Cambridge University Press.

Foss, Kirsten, Nicolai Foss, Sandra K. Klein, and Peter G. Klein. 2007. “The Entrepreneurial Organization of Heterogeneous Capital." Journal of Management Studies 44, no. 7: 1165-86.

Higgs, Robert. 1997. "Regime Uncertainty." Independent Review 1, no. 4: 561-90.

Hoppe, Hans-Hermann. 1989. A Theory of Socialism and Capitalism. Norwell, Mass.: Kluwer Academic Publishers.

Hoppe, Hans-Hermann, and Walter Block. 2002. “On Property and Exploitation." International Journal of Value-Based Management 15, no. 3: 225-36.

Hülsmann, Jörg Guido. 2006. "The Political Economy of Moral Hazard." Politická ekonomie 54, no. 1: 35-47.

Kinsella, N. Stephan. 1995. "Legislation and the Discovery of Law in a Free Society." Journal of Libertarian Studies 11, no. 2: 132-81.

-_- 2008. Against Intellectual Property. Auburn, Ala.: Ludwig von Mises Institute.

Kirzner, Israel. 1997. Essays on Capital and Interest: An Austrian Perspective. Brookfield, Vt.: Edward Elgar.

_ 2009. "The Alert and Creative Entrepreneur: A Clarification." Small Business Economics 32, no. 2: 145-52.

—_ 2017. "The Entrepreneurial Market Process-An Exposition." Southern Economic Journal 83, no. 4: 855-68.

Klein, Peter G. 2008. “Opportunity Discovery, Entrepreneurial Action, and Economic Organization." Strategic Entrepreneurship Journal 2: 175-90.

Lewin, Peter, and Howard Baetjer. 2011. "The Capital-Based View of the Firm." Review of Austrian Economics 24, no. 4: 335-54. 
McCloskey, Deirdre. 2010. Bourgeois Dignity: Why Economics Can't Explain the Modern World. Chicago: University of Chicago Press.

Mueller, Dennis C. 2003. The Corporation: Investments, Merger and Growth. London: Routledge.

Rothbard, Murray N. [1962] 2004. Man, Economy, and State, with Power and Market. Scholar's ed. Auburn, Ala.: Ludwig von Mises Institute.

Salerno, Joseph T. 2008. “The Entrepreneur: Real and Imagined." Quarterly Journal of Austrian Economics 11, no. 3: 188-207.

Taleb, Nassim Nicholas. 2012. Antifragile: Things That Gain from Disorder. New York: Random House. 